\title{
Comparison of simulated keratometric changes following wavefront-guided and wavefront- optimized myopic laser-assisted in situ keratomileusis
}

This article was published in the following Dove Press journal:

Clinical Ophthalmology

\section{Wen-Shin Lee \\ Edward E Manche}

Department of Ophthalmology, Byers Eye Institute, Stanford University, Palo Alto, CA, USA
Correspondence: Edward E Manche Byers Eye Institute, Stanford University, 2452 Watson Court, Palo Alto,

CA 94303, USA

Tel + I 6507236995

Fax + I 6507237918

Email edward.manche@stanford.edu
Purpose: The aim of the study was to determine and compare the relationship between change in simulated keratometry $(\mathrm{K})$ and degree of refractive correction in wavefront-guided (WFG) and wavefront-optimized (WFO) myopic laser-assisted in situ keratomileusis (LASIK).

Methods: A total of 51 patients were prospectively randomized to WFG LASIK in one eye and WFO LASIK in the contralateral eye at the Byers Eye Institute, Stanford University. Changes in simulated $\mathrm{K}$ and refractive error were determined at 1 year post-operatively. Linear regression was employed to calculate the slope of change in simulated $\mathrm{K}(\Delta \mathrm{K})$ for change in refractive error $(\Delta \mathrm{SE})$. The mean ratio $(\Delta \mathrm{K} / \Delta \mathrm{SE})$ was also calculated.

Results: The ratio of $\Delta \mathrm{K}$ to $\Delta \mathrm{SE}$ was larger for WFG LASIK compared to WFO LASIK when comparing the slope $(\Delta \mathrm{K} / \Delta \mathrm{SE})$ as determined by linear regression $(0.85 \mathrm{vs} 0.83, p=0.04)$. Upon comparing the mean ratio $(\Delta \mathrm{K} / \Delta \mathrm{SE})$, subgroup analysis revealed that $\Delta \mathrm{K} / \Delta \mathrm{SE}$ was larger for WFG LASIK for refractive corrections of $>3.00 \mathrm{D}$ and $>4.00 \mathrm{D}(0.89 \mathrm{vs} 0.83 ; p=0.0323$ and 0.88 vs $0.83 ; p=0.0466$, respectively). Both linear regression and direct comparison of the mean ratio $(\Delta \mathrm{K} / \Delta \mathrm{SE})$ for refractive corrections $<4.00 \mathrm{D}$ and $>4.00 \mathrm{D}$ revealed no difference in $\Delta \mathrm{K} / \Delta \mathrm{SE}$ between smaller and larger refractive corrections.

Conclusion: WFO LASIK requires a smaller amount of corneal flattening compared to WFG LASIK for a given degree of refractive correction. For both, there was no significant difference in change in corneal curvature for a given degree of refractive error between smaller and larger corrections.

Keywords: LASIK, keratometry, wavefront guided, wavefront optimized

\section{Introduction}

Laser photoablation is used to correct myopia by flattening the cornea proportionally to the intended amount of refractive correction. The degree of change in corneal curvature relative to the amount of corrected myopia is represented by the ratio of change in simulated keratometry $(\mathrm{K})$ to change in spherical equivalent (SE) of refractive error. Understanding this relationship is important for pre-operative planning, as significant flattening of the cornea may yield sub-optimal quality of vision after myopic laser photoablation. ${ }^{1,2}$ These scenarios may be avoided by better predicting the post-operative simulated $\mathrm{K}$ for a given degree of refractive correction.

Additionally, understanding this relationship is relevant when considering cataract extraction and intraocular lens (IOL) implantation in patients with a history of prior myopic laser photoablation. A number of studies have demonstrated that 
keratometric measurements following laser-assisted in situ keratomileusis (LASIK) are frequently overestimated. ${ }^{3}$ This in turn results in the selection of underpowered IOLs with consequent hyperopic surprise. This phenomenon has been demonstrated with various topographers, including manual keratometry, automated keratometry, videokeratography, and IOLMaster. ${ }^{4-11}$ As a result, different methods have been proposed to better calculate IOL power after myopic laser photoablation. ${ }^{11-14}$

A previous study has shown that the ratio of change in simulated $\mathrm{K}$ to change in corrected refractive error is not linear or constant following myopic LASIK. ${ }^{2}$ Instead, for larger refractive errors, there is a smaller change in simulated K relative to degree of refractive correction. ${ }^{2}$ The same investigators demonstrated that custom LASIK results in a greater ratio of change in corneal curvature to degree of myopic correction compared to conventional LASIK. ${ }^{2}$ Whether there is a significant difference in this ratio between wavefront-optimized (WFO) vs wavefront-guided (WFG) LASIK has yet to be determined.

Both WFO and WFG LASIK yield outstanding clinical outcomes and induce fewer higher order aberrations relative to conventional LASIK. ${ }^{15,16}$ Here, the relationship between induced change in corneal curvature and change in refractive error for both WFO and WFG LASIK was investigated, and furthermore, any difference in this relationship when comparing the two ablation profiles was determined.

\section{Methods}

A total of 102 eyes of 51 patients undergoing LASIK were enrolled from the refractive surgery service at Byers Eye Institute, Stanford University. Patients were followed prospectively for 1 year post-operatively. The inclusion criteria for this study were as previously reported: ${ }^{15}<12.00 \mathrm{D}$ of myopia with $<3.00 \mathrm{D}$ of astigmatism, stable refraction with $<0.50 \mathrm{D}$ change in sphere and cylinder in the prior year, best-corrected visual acuity (BCVA) of 20/20 or better in both eyes, cessation of soft contact lens use for $\geq 7$ days prior to the pre-operative visit, and age $\geq 21$ years.

The study was conducted at the Stanford Eye Laser Center and adhered to the tenets of the Declaration of Helsinki as well as the Health Insurance Portability and Accountability Act. Written informed consent was obtained from all the patients to participate in this study. Institutional review board (IRB) approval was obtained from the Stanford University IRB. The trial was publicly registered with the National Institutes of Health at https://www.ClinicalTrials.gov/ (NCT01135719).
A computer-generated schedule was utilized to randomize patients to WFG LASIK (VISX CustomVue Star S4 IR excimer laser system; Abbot Medical Optics) in one eye and WFO LASIK (WaveLight Allegretto Wave Eye-Q $400 \mathrm{~Hz}$ excimer laser system; Alcon Surgical) in the contralateral eye. Allegretto used a $6.5 \mathrm{~mm}$ optical zone with a variable blend zone. VISX employed an optical zone of $6.0 \mathrm{~mm}$ with a blend zone out to $8.0 \mathrm{~mm}$. Both platforms resulted in $\sim 15 \mu \mathrm{m}$ of tissue removal per diopter of corrected myopia. The Intralase iFS 150 femtosecond laser (Abbot Medical Optics) was used for flap creation, with flaps standardized to $9.0 \mathrm{~mm}$ in diameter and $105 \mu \mathrm{m}$ in thickness.

A manifest refraction was performed at the pre-operative visit and at the post-operative year 1 visit. The difference between the SE at these visits was used to determine the amount of refractive change at post-operative year 1. At both visits, a $12 \mathrm{~mm}$ vertex distance was used to shift the refraction from the spectacle plane to the corneal plane. Scanning-slit topography (Orbscan; Bausch \& Lomb) was used to determine mean corneal topography at the pre-operative visit and at the post-operative year 1 visit. The difference between these measurements was used to determine the change in simulated $\mathrm{K}$ at post-operative year 1 .

A linear regression was then employed using the equation, $\Delta \mathrm{K}=\alpha+\beta[\Delta \mathrm{SE}]$, to assess the relationship between change in simulated $K(\Delta K)$ relative to change in refractive error $(\triangle \mathrm{SE})$ for both the WFO and WFG LASIK groups. In this equation, the slope $\beta$ represented the ratio of change in simulated $\mathrm{K}$ to change in $\mathrm{SE}(\Delta \mathrm{K} / \Delta \mathrm{SE})$. The data from the two groups were pooled, and a joint pooled cross-section regression was employed using a standard $F$ test of the equality of the coefficients to compare the slopes $(\beta)$ for the WFO and WFG LASIK groups, respectively.

The ratios of change in simulated $K$ to change in SE $(\Delta \mathrm{K} / \Delta \mathrm{SE})$ were alternatively compared between the two ablation profiles by calculating the mean values of this ratio for each group followed by the two-variable $t$-test to compare the mean values after confirming normality by the Shapiro-Wilk test. All subgroups were tested for normality using the Shapiro-Wilk test. The Wilcoxon rank-sum test was used to compare non-normally distributed data. The two-variable $t$-test was used to compare normally distributed data. Subgroup analysis was performed comparing the mean values of the ratio $(\Delta \mathrm{K} / \Delta \mathrm{SE})$ between the two ablation profiles for changes in refractive error of $>2.00 \mathrm{D},>3.00 \mathrm{D}$, and $>4.00 \mathrm{D}$. Finally, the mean values of the ratio $(\Delta \mathrm{K} / \Delta \mathrm{SE})$ for changes in refractive error of $<4.00 \mathrm{D}$ vs $>4.00 \mathrm{D}$ were compared within each group. 


\section{Results}

There were no significant differences in pre-operative SE of refractive error, cylindrical error, or $\mathrm{K}$ values between the WFG and WFO LASIK groups (Table 1).

Linear regression modeling using the equation, $\Delta \mathrm{K}=$ $\alpha+\beta[\Delta \mathrm{SE}]$, demonstrated several key findings (Table 2 and Figure 1). For both ablation profiles, the slope ( $\beta$ ) was positive $(p<0.0001)$, which was consistent with a positive linear correlation between $\Delta \mathrm{K}$ and $\Delta \mathrm{SE}$. The difference between the estimate of $\beta$ between the WFG and WFO LASIK groups was statistically significant $(0.85$ vs 0.83 , respectively, $p=0.04$ ), revealing that the degree of change in simulated $\mathrm{K}$ per unit of change in SE was larger in the WFG compared to the WFO LASIK cohort.

The estimate of $\alpha$ was positive for both the WFG and WFO LASIK groups; however, this did not reach statistical significance for either group ( $p=0.399$ and $p=0.9476$, respectively). Thus, the relationship between $\Delta \mathrm{K}$ and $\Delta \mathrm{SE}$ for both ablation profiles did not include a positive y-intercept. Therefore, the ratio $(\Delta \mathrm{K} / \Delta \mathrm{SE})$ in this model was constant between small and large changes in refractive error. That is, correcting smaller and larger refractive errors required similar corresponding flattening in corneal curvature for both ablation profiles.

To more thoroughly investigate this relationship, the mean values of the ratio $(\Delta \mathrm{K} / \Delta \mathrm{SE})$ were compared between changes in refractive error $<4.00 \mathrm{D}$ and $>4.00 \mathrm{D}$ for both WFG and WFO LASIK (Table 3 and Figure 2). In the WFG LASIK group, there was no statistically significant difference between the ratio for refractive corrections of $<4.00 \mathrm{D}$ compared to $>4.00 \mathrm{D}$ ( 0.91 vs 0.88 , respectively, $p=0.5591$ ). In the WFO group, there was also no statistically significant difference between the ratio for refractive corrections of $<4.00 \mathrm{D}$ compared to $>4.00 \mathrm{D}(0.85 \mathrm{vs} 0.83$, respectively, $p=0.6311)$. Thus, both linear regression modeling and direct comparison of the mean values of the ratio $(\Delta \mathrm{K} / \Delta \mathrm{SE})$ between patients with smaller $(<4.00 \mathrm{D})$ and larger $(>4.00 \mathrm{D})$ refractive errors revealed that the ratio $(\Delta \mathrm{K} / \Delta \mathrm{SE})$ did not vary with degree of corrected refractive error.

There was no statistically significant difference when comparing the mean ratio $(\Delta \mathrm{K} / \Delta \mathrm{SE})$ between the WFG and
WFO LASIK groups as a whole (0.89 vs $0.84, p=0.0913)$ (Table 4). In subgroup analyses comparing WFG and WFO LASIK for changes in refractive error of $>2.00 \mathrm{D},>3.00 \mathrm{D}$, and $>4.00 \mathrm{D}$, all subgroups demonstrated a larger ratio $(\Delta \mathrm{K} / \Delta \mathrm{SE})$ for the WFG LASIK subgroups compared to the WFO LASIK subgroups, with statistical significance reached in the $>3.00 \mathrm{D}$ and $>4.00 \mathrm{D}$ subgroups $(0.89$ vs $0.83 ; p=0.0323$ and 0.88 vs $0.83 ; p=0.0466$, respectively). Thus, for larger degrees of refractive correction, WFG LASIK required more corneal flattening for a given change in refractive error when compared to WFO LASIK.

\section{Discussion}

Both WFO and WFG photoablation have become widely used among refractive surgeons in recent years, as these techniques result in a lower post-operative induction of higher order aberrations relative to conventional therapies. ${ }^{16}$ Although both WFO and WFG LASIK have been shown to result in excellent visual outcomes, in head-to-head comparison, WFG LASIK results in less residual refractive error, improved uncorrected distance visual acuity, and improved contrast sensitivity. ${ }^{15}$ Despite the demonstrated advantages of WFG compared to WFO LASIK, both modalities continue to be widely used among refractive surgeons. Thus, understanding the extent of corneal flattening induced for a given degree of refractive correction with both ablation profiles is important for both pre-operative planning and future IOL selection.

The present study demonstrates that WFO LASIK requires a smaller amount of corneal flattening for a given degree of myopic refractive correction compared to WFG LASIK. This was demonstrated both in comparing the slope $\beta$ in the linear regression model $(\Delta \mathrm{K}=\alpha+\beta[\Delta \mathrm{SE}])$ and directly comparing the mean ratio $(\Delta \mathrm{K} / \Delta \mathrm{SE})$ between WFG and WFO LASIK. Although comparing the mean ratio $(\Delta \mathrm{K} / \Delta \mathrm{SE})$ between the two ablation profiles for the entire cohort did not reveal a statistically significant difference, upon subgroup analysis it was revealed that at higher degrees of refractive correction $(>3.00 \mathrm{D}$ and $>4.00 \mathrm{D})$, WFG LASIK resulted in a larger ratio of change in simulated $\mathrm{K}$ to change in refractive error compared to WFO LASIK. In other words, at higher degrees

Table I Pre-op refractive measures

\begin{tabular}{llll}
\hline Ablation profile & Pre-op SE & Pre-op cyl & Pre-op K \\
\hline WFG LASIK $(n=5 \mathrm{I})$ & $-4.56 \pm \mathrm{I} .9 \mathrm{I}(-\mathrm{I} .23$ to -8.63$)$ & $0.82 \pm 0.72(0-2.8 \mathrm{I})$ & $43.8 \pm 0.92(42.37-46.24)$ \\
WFO LASIK $(\mathrm{n}=5 \mathrm{I})$ & $-4.6 \mathrm{I} \pm \mathrm{I} .66(-\mathrm{I} .23$ to $-7.7 \mathrm{I})$ & $0.79 \pm 0.80(0-2.90)$ & $43.7 \pm 0.98(4 \mathrm{I} .62-45.92)$ \\
& $p=0.8729$ & $p=0.5049$ & $p=0.75 \mathrm{I} 8$ \\
\hline
\end{tabular}

Notes: cyl, cylindrical error; K, simulated keratometry.

Abbreviations: LASIK, laser-assisted in situ keratomileusis; pre-op, pre-operative; SE, spherical equivalent; WFG, wavefront-guided; WFO, wavefront-optimized. 
Table 2 Estimation results for the model $(\Delta \mathrm{K}=\alpha+\beta[\Delta \mathrm{SE}])$

\begin{tabular}{|c|c|c|c|c|}
\hline \multirow[t]{2}{*}{ Parameter } & \multirow[t]{2}{*}{ Estimate } & \multirow[t]{2}{*}{$p$-value } & \multicolumn{2}{|c|}{$\begin{array}{l}\text { 95\% confidence } \\
\text { interval }\end{array}$} \\
\hline & & & $\begin{array}{l}\text { Lower } \\
\text { limit }\end{array}$ & $\begin{array}{l}\text { Upper } \\
\text { limit }\end{array}$ \\
\hline \multicolumn{5}{|l|}{ WFG LASIK } \\
\hline$A$ & 0.17 & 0.399 & -0.23 & 0.57 \\
\hline B & 0.85 & $<0.000 \mathrm{I}$ & 0.76 & 0.93 \\
\hline$R^{2}$ & 0.89 & & & \\
\hline Observations (n) & 51 & & & \\
\hline \multicolumn{5}{|l|}{ WFO LASIK } \\
\hline$A$ & 0.01 & 0.9476 & -0.42 & 0.45 \\
\hline B & 0.83 & $<0.000$ I & 0.73 & 0.93 \\
\hline$R^{2}$ & 0.86 & & & \\
\hline Observations (n) & 51 & & & \\
\hline \multicolumn{5}{|l|}{ Test of equality } \\
\hline F-statistic ${ }^{\mathrm{a}}$ for $\alpha$ & 2.54 & 0.08 & & \\
\hline F-statistic for $\beta$ & 4.42 & 0.04 & & \\
\hline
\end{tabular}

Notes: $\alpha$, constant in the linear regression; $\beta$, slope in the linear regression; and $R^{2}$, square of the correlation coefficient in the linear regression. ${ }^{2}$ For equality of the coefficients across the two ablation profiles.

Abbreviations: LASIK, laser-assisted in situ keratomileusis; WFG, wavefrontguided; WFO, wavefront-optimized.

of refractive correction, WFO LASIK produced a smaller degree of corneal flattening compared to WFG LASIK. As excessive corneal flattening may result in sub-optimal visual outcomes, ${ }^{1,2}$ these results suggest that WFO LASIK may be preferable to WFG LASIK in cases when over flattening of the cornea is a concern, including patients with a higher degree of myopia and concurrent flatter $\mathrm{K}$ values.

With regard to post-LASIK IOL selection, corneal power calculations are often overestimated following myopic laser photoablation, which results in the selection of underpowered IOLs with consequent hyperopic surprise. ${ }^{4-11}$ Our results indicate that at higher degrees of refractive correction, the ratio $(\Delta \mathrm{K} / \Delta \mathrm{SE})$ is larger for WFG LASIK compared to WFO LASIK. That is, the ratio of change in corneal curvature to change in refractive error is closer to 1:1 for WFG LASIK at higher degrees of refractive correction. As such, there may be a smaller degree of error in post-operative corneal power calculations for WFG LASIK compared to WFO LASIK at higher degrees of refractive correction, which may have implications for future IOL selection.

The present study also revealed that there was no significant difference in the ratio $(\Delta \mathrm{K} / \Delta \mathrm{SE})$ when comparing smaller to larger degrees of refractive error. These results contrast with prior work demonstrating smaller amounts of refractive correction resulting in proportionally larger changes in corneal curvature when compared to larger amounts of refractive correction for both custom and conventional LASIK. ${ }^{2}$ This discrepancy may be related to study

\section{A $\quad$ VISX}
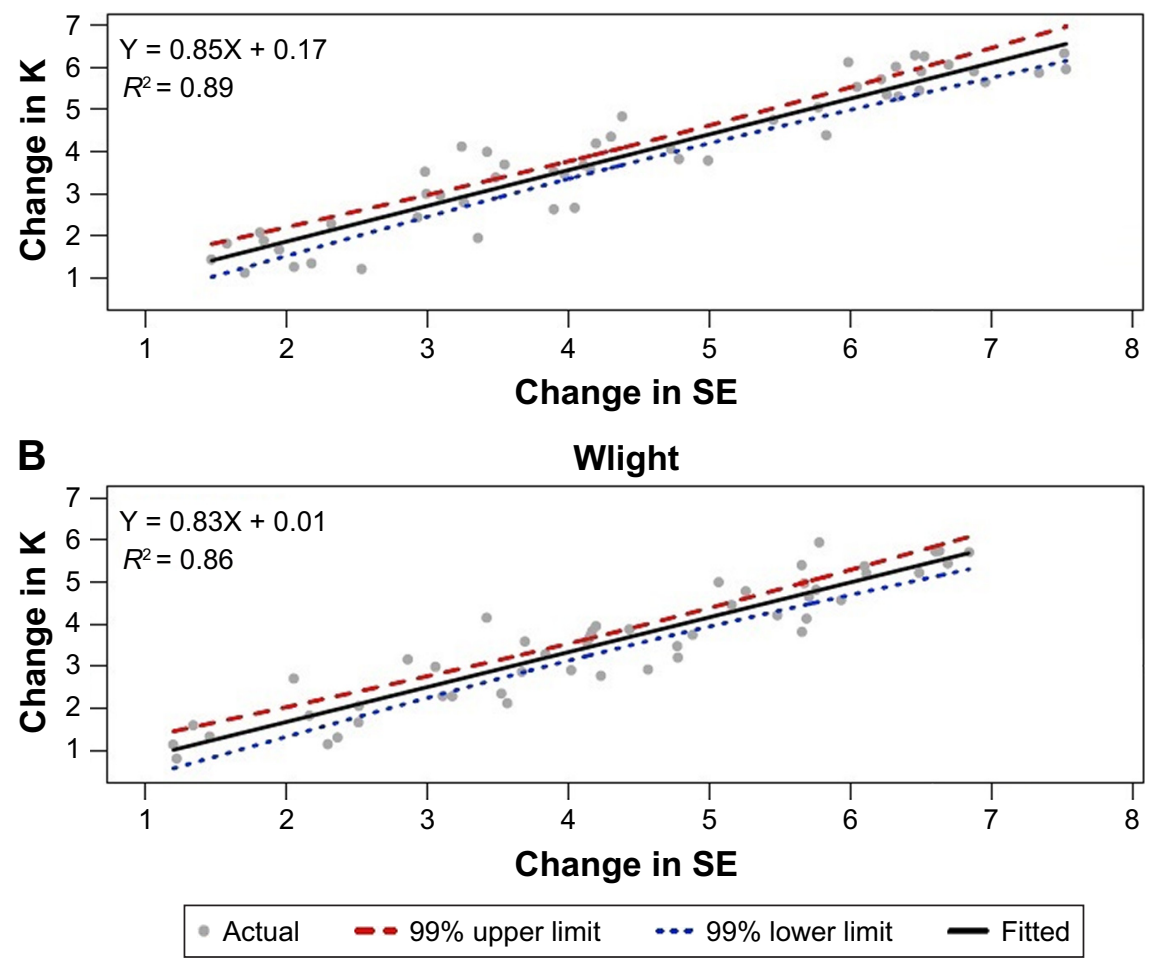

Figure I Linear regression of the change in simulated $\mathrm{K}$ vs the change in SE induced by WFG LASIK (A) and by WFO LASIK (B).

Abbreviations: K, keratometry; LASIK, laser-assisted in situ keratomileusis; SE, spherical equivalent; WFG, wavefront-guided; WFO, wavefront-optimized; Wlight, wavelight. 
Table 3 Comparison of the ratio of change in $\mathrm{K}$ to change in SE by the amount of refractive correction

\begin{tabular}{|c|c|c|c|c|}
\hline \multirow[t]{3}{*}{ Parameter } & \multicolumn{4}{|c|}{ Change in $\mathrm{SE}^{\mathrm{a}}$ (D) } \\
\hline & \multicolumn{2}{|l|}{ WFG LASIK } & \multicolumn{2}{|l|}{ WFO LASIK } \\
\hline & $<4.00$ & $>4.00$ & $<4.00$ & $<4.00$ \\
\hline \multicolumn{5}{|l|}{$\overline{R a t i o}$} \\
\hline Mean & 0.91 & 0.88 & 0.85 & 0.83 \\
\hline SD & 0.22 & 0.09 & 0.23 & 0.10 \\
\hline Mean pre-op K, D (range) & $43.5(42.4-45.9)$ & $44.0(42.5-45.1)$ & $43.6(4 I .6-45.9)$ & $43.8(42.2-45.9)$ \\
\hline Observations, n & 24 & 28 & 21 & 31 \\
\hline$p$-value (ratio) & 0.5591 & & 0.6311 & \\
\hline$p$-value (pre-op K) & 0.08 & & 0.3365 & \\
\hline
\end{tabular}

Note: anduced by LASIK.

Abbreviations: LASIK, laser-assisted in situ keratomileusis; pre-op, pre-operative; SE, spherical equivalent; WFG, wavefront-guided; WFO, wavefront-optimized.

methodology, as the refractive error in the previous study was measured at the spectacle plane, ${ }^{2}$ whereas our study was adjusted for vertex distance to calculate refractive error at the corneal plane. In the absence of this adjustment, non-linear effects due to change in the relative impact of vertex distance with increased refractive error may have contributed to the difference in the ratio $(\Delta \mathrm{K} / \Delta \mathrm{SE})$ between smaller and larger degrees of refractive error demonstrated previously. ${ }^{2}$

Other studies have demonstrated smaller amounts of refractive correction resulting in proportionally larger changes in corneal curvature when compared to larger amounts of refractive correction in myopic photorefractive keratectomy (PRK). ${ }^{17,18}$ At that time, it was postulated that this phenomenon might be related to the increased amount of stromal tissue removal required for larger corrections. That is, increased stromal tissue removal would be expected to result in a greater reduction in axial length relative to smaller corrections; a greater contribution to myopic correction through reduction of axial length for larger corrections might in turn require less corneal flattening proportionally. It is unclear why this effect was not demonstrated in the setting of LASIK in the present study,
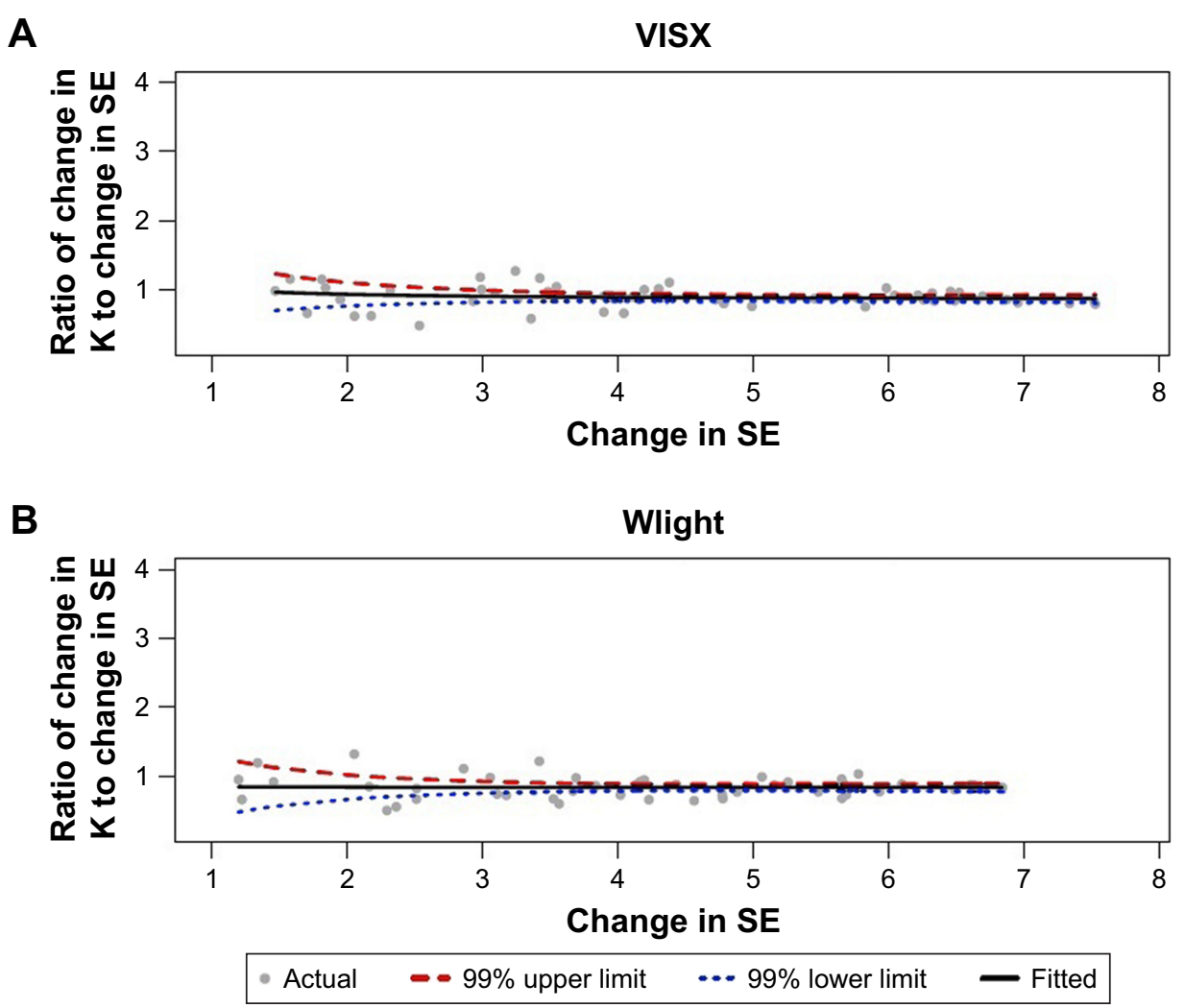

Figure 2 Ratio of change in simulated $\mathrm{K}$ to change in SE plotted by the amount of refractive correction for WFG LASIK (A) and WFO LASIK (B).

Abbreviations: K, keratometry; LASIK, laser-assisted in situ keratomileusis; SE, spherical equivalent; WFG, wavefront-guided; WFO, wavefront-optimized; Wlight, wavelight. 
Table 4 Comparisons of the ratio of change in $\mathrm{K}$ to change in SE between WFG LASIK and WFO LASIK

\begin{tabular}{|c|c|c|c|c|c|c|c|c|}
\hline \multirow[t]{3}{*}{ Parameter } & \multicolumn{2}{|c|}{ Full sample } & \multicolumn{6}{|c|}{ Change in SE (D) ${ }^{a}$} \\
\hline & \multirow[t]{2}{*}{ WFG } & \multirow[t]{2}{*}{ WFO } & \multicolumn{2}{|l|}{$>2.00$} & \multicolumn{2}{|l|}{$>3.00$} & \multicolumn{2}{|l|}{$>4.00$} \\
\hline & & & WFG & WFO & WFG & WFO & WFG & WFO \\
\hline \multicolumn{9}{|l|}{ Ratio } \\
\hline Mean & 0.89 & 0.84 & 0.88 & 0.83 & 0.89 & 0.83 & 0.88 & 0.83 \\
\hline SD & 0.16 & 0.16 & 0.16 & 0.16 & 0.13 & 0.12 & 0.09 & 0.10 \\
\hline Observations & 51 & 51 & 45 & 47 & 38 & 40 & 28 & 31 \\
\hline$p$-value & 0.0913 & & 0.1184 & & 0.0323 & & 0.0466 & \\
\hline
\end{tabular}

Note: anduced by LASIK.

Abbreviations: LASIK, laser-assisted in situ keratomileusis; SE, spherical equivalent; WFG, wavefront-guided; WFO, wavefront-optimized.

although one possibility is that LASIK flap creation alters this effect.

The increased contribution to reduction in axial length for larger ablations may also be responsible for the difference in the ratio $(\Delta \mathrm{K} / \Delta \mathrm{SE})$ between the VISX (WFG) and Allegretto (WFO) platforms demonstrated in the present study. The Allegretto optical zone is $6.5 \mathrm{~mm}$ with a variable blend zone, compared to $6.0 \mathrm{~mm}$ with an $8.5 \mathrm{~mm}$ blend zone for VISX. Consequently, the Allegretto has a $\sim 10 \%$ larger optical zone which may result in increased stromal ablation. This increased tissue removal and thus increased contribution to reduction in axial length may account for the relatively smaller change in corneal curvature for WFO compared to WFG LASIK. Although it is possible to program the Allegretto to employ a $6.0 \mathrm{~mm}$ optical zone, the default $6.5 \mathrm{~mm}$ optical zone was utilized, which is standard practice in the United States and worldwide.

There are several limitations to the present study. First, two distinct laser systems (VISX vs Allegretto) with two different ablation profiles (WFG vs WFO), repetition rates ( 6 to $20 \mathrm{~Hz}$ variable vs $400 \mathrm{~Hz}$ ), and optical treatment zone sizes were utilized in this study. Thus, although our results indicate that WFO LASIK using the Allegretto results in a relatively smaller change in corneal curvature for a given degree of myopic refractive correction compared to WFG LASIK using the VISX, this finding may not generalize to WFO and WFG ablation patterns on different laser systems. In addition, the validity of our findings was dependent on accurate post-operative simulated $\mathrm{K}$ measurements taken at the $3.0 \mathrm{~mm}$ zone, which may be less accurate after refractive surgery, ${ }^{6,19-24}$ although prior literature has demonstrated good agreement in anterior $\mathrm{K}$ measurements between Orbscan in virgin eyes compared to post-keratorefractive surgery eyes. ${ }^{25}$ As such, anterior corneal curvature measurements may have been a suitable alternative to simulated K. Also, a standardized index of refraction for the cornea produces simulated $\mathrm{K}$ values from anterior corneal curvature measurements, but there is actually individual variation in the corneal index of refraction influenced by epithelial thickness and optical zone diameter. This may account for erroneous simulated $\mathrm{K}$ measurements. In the future, studies of keratometric changes in the setting of refractive surgery may benefit from newer imaging modalities such as anterior segment optical coherence tomography or Scheimpflug imaging.

\section{Conclusion}

The findings of the present study indicate that WFO LASIK results in a relatively smaller change in corneal curvature for a given degree of myopic refractive correction compared to WFG LASIK. Additionally, for both ablation profiles there was no difference in the change in corneal curvature for a given degree of myopic refractive correction when comparing smaller vs larger refractive corrections. These findings may need to be taken into consideration for both pre-operative planning and post-operative IOL selection in the setting of WFO and WFG LASIK.

\section{Acknowledgments}

The abstract of this paper was presented at the American Society of Cataract and Refractive Surgery (ASCRS) 2017 Annual Meeting as a conference talk with interim findings. The paper's abstract was published in "Paper Abstracts" in the American Society of Cataract and Refractive Surgery (ASCRS) 2017 Annual Meeting Program and Abstracts.

\section{Disclosure}

Dr Manche is an equity owner in RxSight, Inc.. He also holds equity and patents in Seros Medical, LLC. He serves as a consultant for Avedro, Alcon, Carl Zeiss Meditec, Johnson and Johnson Vision and Shire. He conducts sponsored research with Alcon, Allergan, Avellino Laboratories, Inc., Avedro, Carl Zeiss Meditec, Ocular Therapeutix, Inc., and Presbia, Inc. The authors report no other conflicts of interest in this work. 


\section{References}

1. Hammond SD Jr, Puri AK, Ambati BK. Quality of vision and patient satisfaction after LASIK. Curr Opin Ophthalmol. 2004;15(4):328-332.

2. Leng C, Feiz V, Modjtahedi B, Moshirfar M. Comparison of simulated keratometric changes induced by custom and conventional laser in situ keratomileusis after myopic ablation: retrospective chart review. J Cataract Refract Surg. 2010;36(9):1550-1555.

3. American Academy of Ophthalmology. Basic and Clinical Science Course. Refractive Surgery, Section 13. San Francisco, CA: American Academy of Ophthalmology; 2014:187.

4. Rosa N, Cennamo G, Rinaldi M. Correlation between refractive and corneal topographic changes after photorefractive keratectomy for myopia. J Refract Surg. 2001;17(2):129-133.

5. Peter R, Hazeghi M, Job O, Wienecke L, Schipper I. Manual keratometry and videokeratography after photorefractive keratectomy. J Cataract Refract Surg. 2000;26(12):1748-1752.

6. Chen S, Hu FR. Correlation between refractive and measured corneal power changes after myopic excimer laser photorefractive surgery. $J$ Cataract Refract Surg. 2002;28(4):603-610.

7. Rosa N, Capasso L, Lanza M, Furgiuele D, Romano A. Reliability of the IOLMaster in measuring corneal power changes after photorefractive keratectomy. J Cataract Refract Surg. 2004;30(2):409-413.

8. Razmju H, Rezaei L, Nasrollahi K, Fesharaki H, Attarzadeh H, Footami FJ. IOLMaster versus manual keratometry after photorefractive keratectomy. J Ophthalmic Vis Res. 2011;6(3):160-165.

9. Seitz B, Langenbucher A, Nguyen NX, Kus MM, Küchle M. Underestimation of intraocular lens power for cataract surgery after myopic photorefractive keratectomy. Ophthalmology. 1999;106(4):693-702.

10. Odenthal MT, Eggink CA, Melles G, Pameyer JH, Geerards AJ, Beekhuis WH. Clinical and theoretical results of intraocular lens power calculation for cataract surgery after photorefractive keratectomy for myopia. Arch Ophthalmol. 2002;120(4):431-438.

11. McCarthy M, Gavanski GM, Paton KE, Holland SP. Intraocular lens power calculations after myopic laser refractive surgery: a comparison of methods in 173 eyes. Ophthalmology. 2011;118(5):940-944.

12. Feiz V, Mannis MJ, Garcia-Ferrer F, et al. Intraocular lens power calculation after laser in situ keratomileusis for myopia and hyperopia: a standardized approach. Cornea. 2001;20(8):792-797.

13. Wang L, Booth MA, Koch DD. Comparison of intraocular lens power calculation methods in eyes that have undergone laser-assisted insitu keratomileusis. Trans Am Ophthalmol Soc. 2004;102:189-196. discussion 196-197.
14. Savini G, Hoffer KJ, Carbonelli M, Barboni P. Intraocular lens power calculation after myopic excimer laser surgery: clinical comparison of published methods. J Cataract Refract Surg. 2010;36(9):1455-1465.

15. He L, Liu A, Manche EE. Wavefront-guided versus wavefrontoptimized laser in situ keratomileusis for patients with myopia: a prospective randomized contralateral eye study. Am J Ophthalmol. 2014; 157(6):1170.e1-1178.e1.

16. Myrowitz EH, Chuck RS. A comparison of wavefront-optimized and wavefront-guided ablations. Curr Opin Ophthalmol. 2009;20(4): 247-250.

17. Moshirfar M, Christiansen SM, Kim G. Comparison of the ratio of keratometric change to refractive change induced by myopic ablation. $J$ Refract Surg. 2012;28(10):675-682.

18. Lee WS, Manche EE. Comparison of simulated keratometric changes following wavefront-guided and wavefront-optimized myopic photorefractive keratectomy. J Refract Surg. 2016;32(8):542-548.

19. Srivannaboon S, Reinstein DZ, Sutton HF, Holland SP. Accuracy of Orbscan total optical power maps in detecting refractive change after myopic laser in situ keratomileusis. J Cataract Refract Surg. 1999; 25(12):1596-1599.

20. Qazi MA, Cua IY, Roberts CJ, Pepose JS. Determining corneal power using Orbscan II videokeratography for intraocular lens calculation after excimer laser surgery for myopia. J Cataract Refract Surg. 2007;33(1): 21-30.

21. Lekhanont K, Nonpassopon M, Wannarosapark K, Chuckpaiwong V. Agreement between clinical history method, Orbscan IIz, and Pentacam in estimating corneal power after myopic excimer laser surgery. PLoS One. 2015;10(4):e0123729.

22. Kim SW, Sun HJ, Chang JH, Kim EK. Anterior segment measurements using Pentacam and Orbscan II 1 to 5 years after refractive surgery. J Refract Surg. 2009;25(12):1091-1097.

23. Ha BJ, Kim SW, Kim SW, Kim EK, Kim TI. Pentacam and Orbscan II measurements of posterior corneal elevation before and after photorefractive keratectomy. J Refract Surg. 2009;25(3):290-295.

24. Hashemi H, Mehravaran S. Corneal changes after laser refractive surgery for myopia: comparison of Orbscan II and Pentacam findings. J Cataract Refract Surg. 2007;33(5):841-847.

25. Lee YW, Choi CY, Yoon GY. Comparison of dual rotating ScheimpflugPlacido, swept-source optical coherence tomography, and Placidoscanning-slit systems. J Cataract Refract Surg. 2015;41(5):1018-1029.
Clinical Ophthalmology

\section{Publish your work in this journal}

Clinical Ophthalmology is an international, peer-reviewed journal covering all subspecialties within ophthalmology. Key topics include: Optometry; Visual science; Pharmacology and drug therapy in eye diseases; Basic Sciences; Primary and Secondary eye care; Patient Safety and Quality of Care Improvements. This journal is indexed on Submit your manuscript here: http://www.dovepress.com/clinical-ophthalmology-journal

\section{Dovepress}

PubMed Central and CAS, and is the official journal of The Society of Clinical Ophthalmology (SCO). The manuscript management system is completely online and includes a very quick and fair peer-review system, which is all easy to use. Visit http://www.dovepress.com/ testimonials.php to read real quotes from published authors. 